\title{
Association between B-lines detected during lung ultrasound and various factors in hemodialysis patients
}

\author{
Shinzo Kuzuhara ${ }^{1,2}$, Shigeru Otsubo ${ }^{1,3^{*}}$, Katsuya Kajimoto ${ }^{4}$, Takashi Akiba $^{2}$ and Kosaku Nitta ${ }^{1}$
}

\begin{abstract}
Background: In recent years, the use of chest ultrasonography to detect lung water has received growing attention in clinical research. Estimation of the number of B-lines using lung ultrasound is now a standard method for the evaluation of pulmonary congestion. In the present study, we examined the relation between the number of B-lines and clinical parameters in hemodialysis patients.

Methods: A total of 49 consecutive patients receiving maintenance hemodialysis were enrolled in this study. Lung ultrasound was performed using Vscan ${ }^{\circledast}$ (GE Healthcare, Japan). Bilateral scanning of the anterior and lateral chest walls was performed with the patient in a supine position just after the start of the hemodialysis therapy. The total number of B-lines was estimated. We investigated the relationships between the number of B-lines and other clinical parameters.

Results: Patient heart rate and the serum log [NT-proBNP] level were positively correlated $(P=0.009$ and 0.003 , respectively), and body weight and the serum albumin and creatinine level were negatively correlated with the number of B-lines ( $P=0.023,0.001$, and 0.011 , respectively).

Conclusions: The number of B-lines was positively correlated with the serum N-terminal pro-brain natriuretic peptide level. Lung ultrasound can quantify lung edema. Body weight and the serum albumin and creatinine level were negatively correlated with the number of B-lines. Careful attention to the presence of pulmonary edema is needed in patients with a low body weight and a low serum albumin and creatinine level.
\end{abstract}

Keywords: B-lines, Hemodialysis, Lung ultrasound, N-terminal pro-brain natriuretic peptide

\section{Background}

Chronic fluid overloading frequently occurs in hemodialysis patients, so one of the major targets of hemodialysis therapy is to maintain a normal extracellular volume status. Preventing volume overload is a central recommendation when it comes to nephrology best-practice guidelines for dialysis patients [1], as this goal is directly associated with hypertension, increased arterial stiffness, left ventricular hypertrophy, heart failure, and ultimately higher rates of mortality and morbidity [2].

\footnotetext{
* Correspondence: sotsubo@hb.tp1.jp

'Department of Medicine, Kidney Center, Tokyo Women's Medical University, Tokyo, Japan

${ }^{3}$ Department of Blood Purification, Tohto Sangenjaya Clinic, 2-13-2 Taishido,

Setagaya-ku, Tokyo 154-0004, Japan

Full list of author information is available at the end of the article
}

To estimate the volume status, several methods have been proposed, such as evaluating the natriuretic peptide levels $[3,4]$, the dimensions and collapsibility of the inferior vena cava [5], chest X-ray signs, and bioelectrical impedance analysis techniques $[6,7]$. However, each of these methods has significant theoretical and practical limitations.

In recent years, the use of chest ultrasonography to detect lung water has received growing attention in clinical research focused on intensive care patients [8] and patients with heart failure [9]. The most commonly observed finding was a comet tail artifact fanning out from the lung-wall interface and spreading upwards to the edge of the screen, previously named a "B-line" (Fig. 1) [10]. In patients with heart failure, the number of B-lines was correlated with the degree of extravascular lung water [11], and 


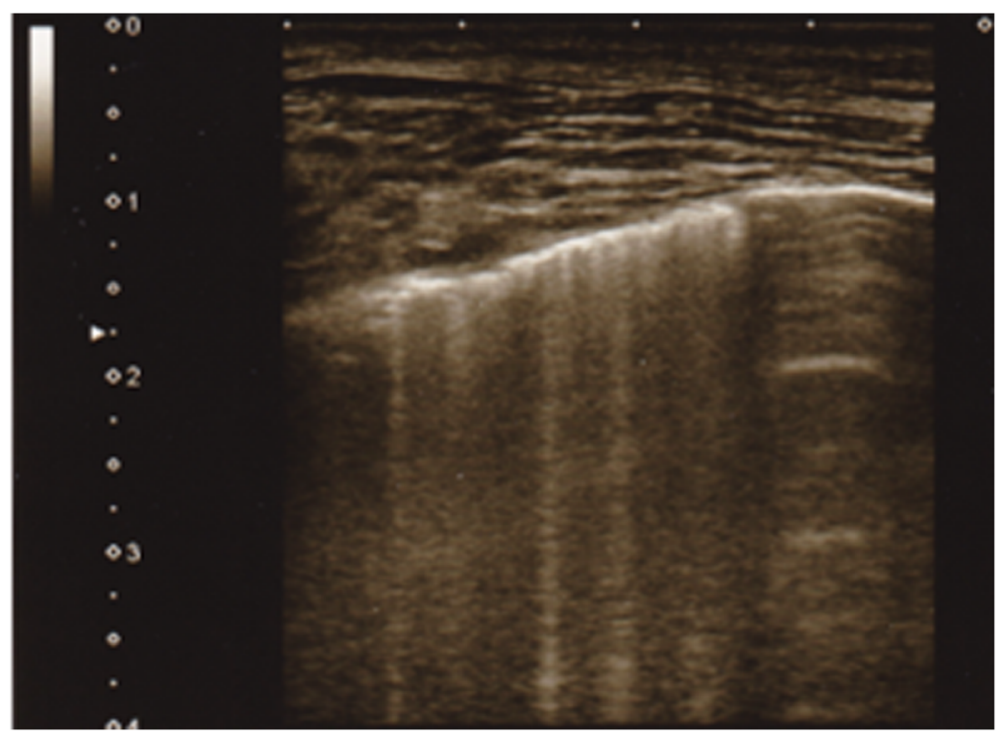

Fig. 1 B-lines: comet tail artifacts fanning out from the lung-wall interface and spreading upwards to the edge of the screen

a reduction in the number of B-lines reflected the efficacy of treatment [1]. Previous studies have also shown that lung ultrasound can detect extravascular lung water and can be used to show a significant reduction after a dialytic session (both hemodialysis and peritoneal dialysis) [12-15]. Existing data suggest that lung ultrasound characteristics might be suitable for assessing the ideal body weight in hemodialysis patients, since this technique is simple, inexpensive, nonionizing, and can easily be performed at the patient's bedside $[16,17]$.

Consequently, estimation of the number of B-lines using lung ultrasound is now a standard method for the evaluation of pulmonary congestion [18]. In the present study, we examined the relation between the number of $\mathrm{B}$-lines and clinical parameters in hemodialysis patients.

\section{Methods}

The proportion of hospitalization for acute heart failure in hemodialysis patients was significantly higher on Monday (approximately 1/3) compared with other days [19]. So we selected patients who underwent hemodialysis therapy on Monday (the first day after weekend interval). A total of 49 consecutive patients receiving maintenance hemodialysis at Sekikawa Hospital on Monday were enrolled in this study. Informed consents were obtained in all patients.

Clinical data including age, sex, duration of hemodialysis therapy, presence of diabetes mellitus and/or hypertension and/or dyslipidemia complications, use of antihypertensive drug, history of coronary artery disease, and the results of biological examinations were collected from the patient's clinical records. Hypertension was defined as a systolic blood pressure of $140 \mathrm{mmHg}$ or higher, a diastolic blood pressure of $90 \mathrm{mmHg}$ or higher, and/or the current use of antihypertensive drugs. Diabetes mellitus was defined as a fasting glucose level $\geq 126 \mathrm{mg} / \mathrm{dL}$, a nonfasting glucose level $\geq 200 \mathrm{mg} / \mathrm{dL}$, or the use of medication. Dyslipidemia was defined as a low-density lipoprotein-cholesterol level $\geq 140 \mathrm{mg} / \mathrm{dL}$, a high-density lipoprotein-cholesterol level $<40 \mathrm{mg} / \mathrm{dL}$, a triglyceride level $\geq 150 \mathrm{mg} / \mathrm{dL}$, or the use of medication.

A peripheral blood sample was obtained before hemodialysis during the first session of the week. The serum N-terminal pro-brain natriuretic peptide (NTproBNP) level in the pre-dialysis blood sample was measured using an electrochemiluminescence immunoassay on an Elecsys platform (Roche, Basel, Switzerland).

Lung ultrasound was performed at the first session of the week, the same time of peripheral blood sample preparation, using Vscan ${ }^{\circ}$ (GE Healthcare, Japan), a hand-held ultrasound device with a wide-bandwidth phased-array probe $(1.7-3.5 \mathrm{MHz})$ [20, 21]. Bilateral scanning of the anterior and lateral chest walls was performed with the patient in a supine position just after the start of the hemodialysis therapy. An intercostal scan with maximum extension of the visual pleural line was performed. The chest wall was divided into eight areas (two anterior and two lateral areas per side), and two scan was obtained for each area [22-26]. The anterior zone of the chest wall was designated from the sternum to the anterior axillary line and was then divided into upper and lower halves (from the clavicle to the third intercostal spaces and from the third space to the diaphragm). The lateral zone was positioned from the anterior axillary line to the posterior axillary line and was also divided into the upper and lower 
halves. Cardiologist, who is blind to the result of blood peripheral blood sample, attempted to detect comet tail artifacts fanning out from the lung-wall interface and spreading to the edge of the screen, which were previously named B-lines (Additional file 1: Movie S1) [23, 24]. The total number of B-lines was estimated. Echocardiographic measurements were obtained at the same time and left ventricular ejection fraction (LVEF) was estimated.

We investigated the relationships between the number of B-lines and other clinical parameters. This study was conducted in accordance with the principles of the Declaration of Helsinki and was permitted by the research ethics committee of Sekikawa Hospital (Approved No. H2705). The data were expressed as the means \pm SD or median (interquartile range, IQR). A simple and multivariate regression analysis was used to examine the relationship between two continuous variables. Because of the skewed distribution of the NT-proBNP levels, the data were normalized using a logarithmic transformation for further statistical analysis. All the statistical calculations were performed using JMP 5.1 software. $P$ values less than 0.05 were considered statistically significant.

\section{Results}

The patient background characteristics are shown in Table 1 . The mean age was $74.5 \pm 11.2$ years. Elderly patients were common in this study. Diabetic nephropathy was the major cause of end-stage kidney disease. Hypertension, diabetes mellitus, and dyslipidemia were present in $83.7,42.9$, and $20.4 \%$ of the study participants, respectively. The mean number of B-lines was $10.8 \pm 4.6$. The results of the biochemistry analyses, including the NTproBNP level, are shown in Table 2. The serum albumin level was relatively low $(3.2 \pm 0.5 \mathrm{~g} / \mathrm{dL})$, and the serum NTproBNP level was relatively high $(13,404$ (4355-28,011) $\mathrm{pg} / \mathrm{mL}$ ) among the study participants.

Table 3 shows the relationships between the number of B-lines and other clinical parameters. Heart rate and the serum log [NT-proBNP] level were positively correlated $(P=0.009$ and 0.003 , respectively), and body weight and the serum albumin and creatinine levels were negatively correlated with the number of B-lines $(P=0.023,0.001$ and 0.011 , respectively). Patient age tended to be positively associate with the number of B-lines $(P=0.055)$. LVEF tended to negatively relate to the number of Blines $(P=0.056)$. In multivariate analysis including body weight and heart rate and the serum albumin, creatinine, and log [NT-proBNP] levels, only the serum log [NT-proBNP] level remained significant relation to the number of B-lines $(P=0.014)$.

\section{Discussion}

We showed that the number of B-lines was positively correlated with heart rate and the serum NT-proBNP
Table 1 Background characteristics of the study participants

\begin{tabular}{|c|c|}
\hline Characteristic & Quantity \\
\hline Gender (M/F) & $24 / 25$ \\
\hline Age (year) & $74.5 \pm 11.2$ \\
\hline Duration of HD (year) & $3.4(2.1-7.2)$ \\
\hline \multicolumn{2}{|l|}{ Primary cause of ESKD, $n(\%)$} \\
\hline Chronic glomerulonephritis & $8(16.3)$ \\
\hline Diabetic nephropathy & $22(44.9)$ \\
\hline Nephrosclerosis & $10(20.4)$ \\
\hline Unknown and others & $9(18.4)$ \\
\hline Hypertension, n (\%) & $41(83.7)$ \\
\hline Diabetes mellitus, $n$ (\%) & $21(42.9)$ \\
\hline Dyslipidemia, n (\%) & $10(20.4)$ \\
\hline Atrial fibrillation, $n(\%)$ & $6(12.2)$ \\
\hline Use of antihypertensive drug, $n$ (\%) & $38(77.6)$ \\
\hline \multicolumn{2}{|l|}{ History of coronary artery disease, $n(\%)$} \\
\hline $\mathrm{PCl}$ & $4(8.2)$ \\
\hline CABG & $3(6.1)$ \\
\hline \multicolumn{2}{|l|}{ Vascular access } \\
\hline Arteriovenous fistula & $43(87.8)$ \\
\hline Arteriovenous graft & $2(4.1)$ \\
\hline Subcutaneously fixed superficial artery & $2(4.1)$ \\
\hline Venous catheter & $2(4.1)$ \\
\hline Body weight (kg) & $52.7 \pm 11.5$ \\
\hline Systolic blood pressure (mmHg) & $141 \pm 26$ \\
\hline Diastolic blood pressure $(\mathrm{mmHg})$ & $73 \pm 16$ \\
\hline Heart rate (beat/minute) & $75 \pm 13$ \\
\hline Ejection fraction (\%) & $60 \pm 12$ \\
\hline B-lines (number) & $10.8 \pm 4.6$ \\
\hline
\end{tabular}

Mean \pm SD, median (interquartile range: IQR)

$H D$ hemodialysis, ESKD end-stage kidney disease, $P C l$ percutaneous coronary intervention, $C A B G$ coronary artery bypass grafting

Table 2 Background characteristics of laboratory data

\begin{tabular}{ll}
\hline Characteristic & Quantity \\
\hline Albumin $(\mathrm{g} / \mathrm{dL})$ & $3.2 \pm 0.5$ \\
Urea nitrogen $(\mathrm{mg} / \mathrm{dL})$ & $51.8 \pm 19.0$ \\
Creatinine $(\mathrm{mg} / \mathrm{dL})$ & $7.57 \pm 2.41$ \\
Sodium $(\mathrm{mEq} / \mathrm{L})$ & $137 \pm 4$ \\
C-reactive protein $(\mathrm{mg} / \mathrm{dL})$ & $0.26(0.10-0.91)$ \\
Hemoglobin $(\mathrm{g} / \mathrm{dL})$ & $10.4 \pm 1.2$ \\
NT-proBNP $(\mathrm{pg} / \mathrm{mL})$ & $13,650(4355-28,011)$ \\
$\log [\mathrm{NT}-$ ProBNP $(\mathrm{pg} / \mathrm{mL})]$ & $9.26 \pm 1.33$ \\
\hline
\end{tabular}

Mean $\pm S D$, median (interquartile range: IQR)

NT-proBNP N-terminal pro-brain natriuretic peptide 
Table 3 The relationship between the number of B-lines and other clinical parameters

\begin{tabular}{lll}
\hline & $r$ & $P$ value \\
\hline Age (years) & 0.276 & 0.055 \\
Duration of HD (year) & 0.026 & 0.576 \\
Body weight (kg) & -0.325 & 0.023 \\
Systolic blood pressure (mmHg) & -0.103 & 0.479 \\
Diastolic blood pressure (mmHg) & 0.013 & 0.928 \\
Heart rate (beat/minute) & 0.371 & 0.009 \\
Ejection fraction (\%) & -0.275 & 0.056 \\
Albumin (g/dL) & -0.444 & 0.001 \\
Urea nitrogen (mg/dL) & -0.159 & 0.276 \\
Creatinine (mg/dL) & -0.360 & 0.011 \\
Sodium (mEq/L) & -0.248 & 0.085 \\
C-reactive protein (mg/dL) & 0.063 & 0.666 \\
Hemoglobin (g/dL) & -0.197 & 0.175 \\
NT-ProBNP & 0.523 & $<0.001$ \\
log [NT-ProBNP] & 0.447 & 0.002 \\
\hline
\end{tabular}

HD hemodialysis, NT-proBNP N-terminal pro-brain natriuretic peptide

level, while it was negatively correlated with the body weight and the serum albumin and creatinine level.

Lung ultrasound assessments of extravascular lung water based on the number of B-lines provide an excellent diagnostic alternative, expanding the already established role of transthoracic echocardiography for patients with heart failure [2, 27-29]. Bedetti et al. compared lung ultrasound information obtained by experienced echocardiologists and by inexperienced echocardiographer with very limited (30') dedicated training on B-lines assessment and reveal, there was a significant, tight correlation $(r=0.958, p<0.001)$ between the two observations in the same patient [30]. B-lines can be evaluated anywhere (including extreme environmental conditions using pocket-sized instruments to detect high-altitude pulmonary edema), anytime (during dialysis), by anyone (even a novice sonographer after $1 \mathrm{~h}$ of training), and on anybody (since the chest acoustic window usually remains patent even when an echocardiography is not feasible) [18]. The pre-dialysis number of B-lines significantly correlated with a whole body bioimpedance spectroscopy device-derived extracellular water in hemodialysis patients [31]. Vitturi et al. investigated lung and bioimpedance spectroscopy results immediately before and after dialysis and reported that a reduction in the number of B-lines was correlated with fluid loss as a result of hemodialysis, conforming that lung ultrasound can identify extravascular lung water. The number of post-dialysis B-lines is correlated with the residual weight assessed using bioimpedance, suggesting a role for ultrasound in the management of hemodialysis patients [32]. The serum NT-proBNP level is influenced not only by heart function but also by the volume status. Among nondialysis patients, lung congestion was correlated with the NT-proBNP level [22]. Natriuretic peptides may directly enhance capillary permeability, an effect that may explain the association in addition to filling pressure alone [33]. In this study, we also showed a positive and independent relationship between the number of B-lines and the serum NT-proBNP level in hemodialysis patients.

We also showed that the number of B-lines was positively correlated with heart rate and negatively correlated with body weight and the serum albumin and creatinine level. Volume overload results in lung congestion and also activates the sympathetic nervous system which increases the heart rate. Hypoalbuminemia is common in heart failure patients [34, 35]. Two mechanisms have been proposed to explain the relationship between hypoalbuminemia and congestion. On the one hand, an increase in vascular permeability mediated by an increase in hydrostatic venous pressure may increase the transcapillary escape rate of albumin from the intravascular to the extravascular space [36]; on the other hand, it is possible that intestinal congestion favors albumin enteric losses [37]. It is well documented that a decrease in the body mass index is correlated with an increased mortality rate in patients with heart failure $[38,39]$. Serum level of albumin was positively related to body weight in our study participants $(r=0.332, P=0.020$, data not shown). Both hypoalbuminemia and body weight loss are result of malnutrition. That may be the reason of the relationship between B-lines and body weight. Giuseppe et al. previously reported that physical functioning was inversely associated with the number of Blines and patient age and was positively associated with the serum albumin level [40]. In our study, patient age tended to be positively associate with the number of B-lines $(P=0.055)$. In elderly patients, hypoalbuminemia, body weight loss (which results in reduction of serum creatinine level), and a low level of physical functioning are known to affect each other. Under such conditions, lung congestion, which can be detected by lung ultrasound as B-lines, should be considered.

Left ventricular systolic dysfunction may cause overhydration which result in lung congestion. On the other hand, overhydration may cause lung congestion and increase venous return volume and ventricular filling, thereby increase the stroke volume by the Frank-Starling mechanism when LVEF is preserved. There are conflicting result about the relationship between the number of $\mathrm{B}$ lines and LVEF. Mallamaci et al. [12] used this technique in a population of 75 hemodialysis patients and showed the number of B-lines was negatively associated with an LVEF. But in other study, Siriopol et al. reported the 
number of B-lines was not related to LVEF [31]. The differences are most certainly the result of differences in study populations. In Siriopol et al.'s study, the patients (being younger and possibly with less comorbidities) had a preserved left ventricular systolic function (only 6.3\% of the patients had an LVEF of $<50 \%$ ) [31]. In our study, 11 $(22.4 \%)$ of the patients had an LVEF of $<50 \%$. In hemodialysis patients, the relationship between hydration status, B-lines, and left ventricular systolic function is complex. Accordingly, additional investigation will be needed to clarify the mechanism underlying the association between overhydration and B-lines in hemodialysis patients with a preserved or reduced LVEF.

Our study had some limitations. The sample size was relatively small, and the study was performed at a single institution. B-lines represent the volume status of extravascular lung water. There are some markers of intravascular volume such as cardiothoracic ratio, inferior vena cava, and serum level of atrial natriuretic peptide. Bioimpedance spectroscopy device enables to derive the extracellular water and intracellular water. But we did not have such data, so we could not discuss the relation between these markers. Another limitation of this study was that the investigator who performed lung ultrasound was not blind for the clinical information of the patients such as age, gender, or clinical diagnosis. In addition, the limitations of lung ultrasound are essentially patientdependent. Obese patients may be more difficult to examine because of the thickness of their ribcages and soft tissues. Furthermore, the cross-sectional design prevented us from making any conclusions regarding the effects of treatment. The study participants were also relatively old, their serum albumin levels were relatively low, and their serum NT-proBNP levels were relatively high because of the specificity of our institution.

\section{Conclusions}

The number of B-lines was positively correlated with the serum NT-proBNP level. Lung ultrasound can quantify lung edema noninvasively in real time and in a radiation-free manner, enabling the direct imaging of extravascular lung water. Patient age tended to be positively correlated and the body weight and the serum albumin and creatinine levels were negatively correlated with the number of B-lines. Careful attention to the presence of pulmonary edema is needed in elderly patients with a low body weight and a low serum albumin and creatinine level.

\section{Additional file}

Additional file 1: Movie S1 B-lines detected by lung ultrasound using Vscan $^{\circledast}$ (GE Healthcare, Japan). (mp4 2009 kb)

\section{Abbreviations}

CABG: Coronary artery bypass grafting; ESKD: End-stage kidney disease; HD: Hemodialysis; LVEF: Left ventricular ejection fraction; NT-proBNP: $\mathrm{N}$-terminal pro-brain natriuretic peptide; $\mathrm{PCl}$ : Percutaneous coronary intervention

\section{Acknowledgements}

The authors are very grateful to dialysis staff who understood the clinical importance of this study and who provided high-quality data in Sekikawa Hospital.

Funding

This study was not supported by any grants or funding.

\section{Availability of data and materials}

The datasets during and/or analyzed during the current study are available from the corresponding author on reasonable request.

\section{Authors' contributions}

SK planned the study, searched the literature, assessed the studies, extracted the data, analyzed the data, and prepared the article. SO and KK searched the literature, assessed the studies, and assisted in the article preparation. KK performed the lung echo. KN and TA assisted in the article preparation. All authors read and approved the final manuscript.

\section{Competing interests}

The authors declare that they have no competing interests.

\section{Consent for publication}

Not applicable.

\section{Ethics approval and consent to participate}

This study was approved by the research ethics committee of Sekikawa Hospital (Approved No. H2705) and was conducted under the Declaration of Helsinki.

\section{Author details}

'Department of Medicine, Kidney Center, Tokyo Women's Medical University, Tokyo, Japan. ${ }^{2}$ Department of Nephrology, Sekikawa Hospital, Tokyo, Japan. ${ }^{3}$ Department of Blood Purification, Tohto Sangenjaya Clinic, 2-13-2 Taishido, Setagaya-ku, Tokyo 154-0004, Japan. ${ }^{4}$ Department of Cardiology, Sekikawa Hospital, Tokyo, Japan.

Received: 30 November 2016 Accepted: 10 February 2017

Published online: 08 May 2017

References

1. DOQI. Clinical practice guidelines and clinical practice recommendations for 2006 updates: hemodialysis adequacy, peritoneal dialysis adequacy and vascular access. Am J Kidney Dis. 2006:48(1):S1-322.

2. Tonelli M, Wiebe N, Culleton B, Tonelli M, Wiebe N, Culleton B, et al. Chronic kidney disease and mortality risk: a systematic review. J Am Soc Nephrol. 2006:17:2034-47.

3. Wang AY. Clinical utility of natriuretic peptides in dialysis patients. Semin Dial. 2012;25:326-33.

4. David S, Kumpers P, Seidler V, Biertz F, Haller H, Fliser D. Diagnostic value of N-terminal pro-B-type natriuretic peptide (NT-proBNP) for left ventricular dysfunction in patients with chronic kidney disease stage 5 on hemodialysis. Nephrol Dial Transplant. 2008:23:1370-7.

5. Ando $Y$, Yanagiba S, Asano Y. The inferior vena cava diameter as a marker of dry weight in chronic hemodialyzed patients. Artif Organs. 1995;9:1237-42.

6. Jaeger JQ, Mehta RL. Assessment of dry weight in hemodialysis: an overview. J Am Soc Nephrol. 1999;10:392-403.

7. Donadio C, Consani C, Ardini M, Bernabini G, Caprio F, Grassi G, et al. Estimate of body water compartments and of body composition in maintenance hemodialysis patients: comparison of single and multifrequency bioimpedance analysis. J Ren Nutr. 2005;15:332-44.

8. Jambrik Z, Monti S, Coppola V, Agricola E, Mottola G, Miniati M, et al. Usefulness of ultrasound lung comets as a nonradiologic sign of extravascular lung water. Am J Cardiol. 2004;93:1265-70. 
9. Kajimoto K, Madeen K, Nakayama T, Tsudo H, Kuroda T, Abe T. Rapid evaluation by lung-cardiac-inferior vena cava $(\mathrm{LCl})$ integrated ultrasound for differentiating heart failure from pulmonary disease as the cause of acute dyspnea in the emergency setting. Cardiovasc Ultrasound. 2012;10:49-51.

10. Lichtenstein D. Pneumothorax and introduction to ultrasound signs in the lung. In: Heilmann U, Wilbertz H, Gosling A, editors. General ultrasound in the critically ill. 1st ed. Heidelberg: Springer-Verlag; 2005. p. 105-15.

11. Agricola E, Bove T, Oppizzi M, Marino G, Zangrillo A, Margonato A, et al. "Ultrasound comet-tail images": a marker of pulmonary edema: a comparative study with wedge pressure and extravascular lung water. Chest. 2005;127:1690-5.

12. Mallamaci F, Benedetto FA, Tripepi R, Rastelli S, Castellino P, Tripepi G, et al. Detection of pulmonary congestion by chest ultrasound in dialysis patients. JACC Cardiovasc Imaging. 2010;3:586-94.

13. Noble VE, Murray AF, Capp R, Sylvia-Reardon MH, Steele DJ, Liteplo A Ultrasound assessment for extravascular lung water in patients undergoing hemodialysis. Chest. 2009;135:1433-9.

14. Trezzi M, Torzillo D, Ceriani E, Costantino G, Caruso S, Damavandi PT, et al. Lung ultrasonography for the assessment of rapid extravascular water variation: evidence from hemodialysis patients. Intern Emerg Med. 2013:8:409-15.

15. Panuccio V, Enia G, Tripepi R, Torino C, Garozzo M, Battaglia GG, et al. Chest ultrasound and hidden lung congestion in peritoneal dialysis patients. Nephrol Dial Transplant. 2012;27:3601-5.

16. Gargani L. Lung ultrasound: a new tool for the cardiologist. Cardiovasc Ultrasound. 2011; 27. doi:10.1186/1476-7120-9-6.

17. Bedetti G, Gargani L, Corbisiero A, Frassi F, Poggianti E, Mottola G. Evaluation of ultrasound lung comets by hand held echocardiography. Cardiovasc Ultrasound. 2006;31:4-34.

18. Picano E, Pellikka PA. Ultrasound of extravascular lung water: a new standard for pulmonary congestion. Eur Heart J. 2016;37:2097-104.

19. Minami Y, Kajimoto K, Sato N, Hagiwara N, Takano T. End-stage renal disease patients on chronic maintenance hemodialysis in a hospitalized acute heart failure cohort: Prevalence, clinical characteristics, therapeutic options, and mortality. Int J Cardiol. 2016;224:267-70

20. Cardim N, Fernandez Golfin C, Ferreira D, Aubele A, Toste J, Cobos MA, et al. Usefulness of a new miniaturized echocardiographic system in outpatient cardiology consultations as an extension of physical examination. J Am Soc Echocardiogr. 2011;24:117-24.

21. Liebo MJ, Israel RL, Lillie EO, Smith MR, Rubenson DS, Topol EJ. Is pocket mobile echocardiography the next-generation stethoscope? A crosssectional comparison of rapidly acquired images with standard transthoracic echocardiography. Ann Intern Med. 2011;155:33-8.

22. Liteplo AS, Marill KA, Villen T, Miller RM, Murray AF, Croft PE, et al. Emergency thoracic ultrasound in the differentiation of the etiology of shortness of breath (ETUDES): sonographic B-lines and N-terminal pro-braintype natriuretic peptide in diagnosing congestive heart failure. Acad Emerg Med. 2009;16:201-10.

23. Volpicelli G, Elbarbary M, Blaivas M, Lichtenstein DA, Mathis G, Kirkpatrick AW, et al. International Liaison Committee on Lung Ultrasound (ILC-LUS) for International Consensus Conference on Lung Ultrasound (ICC-LUS). International evidence-based recommendations for point-of-care lung ultrasound. Intensive Care Med. 2012:38:577-91.

24. Volpicelli G, Mussa A, Garofalo G, Cardinale L, Casoli G, Perotto F, et al. Bedside lung ultrasound in the assessment of alveolar-interstitial syndrome. Am J Emerg Med. 2006;24:689-96.

25. Cardinale L, Volpicelli G, Binello F, Garofalo G, Priola SM, Veltri A, et al. Clinical application of lung ultrasound in patients with acute dyspnea: differential diagnosis between cardiogenic and pulmonary causes. Radiol Med. 2009;114:1053-64.

26. Prosen G, Klemen P, Strnad M, Grmec S. Combination of lung ultrasound (a comet-tail sign) and $\mathrm{N}$-terminal pro-brain natriuretic peptide in differentiating acute heart failure from chronic obstructive pulmonary disease and asthma as cause of acute dyspnea in prehospital emergency setting. Crit Care. 2011;15:114-22

27. Volpicelli G, Caramello V, Cardinale L, Mussa A, Bar F, Frascisco MF. Bedside ultrasound of the lung for the monitoring of acute decompensated heart failure. Am J Emerg Med. 2008:26:585-91.

28. Lichtenstein D, Mézière G, Biderman P, Gepner A, Barré $\mathrm{O}$. The comet-tail artifact. An ultrasound sign of alveolar-interstitial syndrome. Am J Respir Crit Care Med. 1997;156:1640-6.
29. Picano E, Frassi F, Agricola E, Gligorova S, Gargani L, Mottola G. Ultrasound lung comets: a clinically useful sign of extravascular lung water. J Am Soc Echocardiogr. 2006;19:356-63.

30. Bedetti G, Gargani L, Corbisiero A, Frassi F, Poggianti E, Mottola G. Evaluation of ultrasound lung comets by hand-held echocardiography. Cardiovasc Ultrasound. 2006:4:34

31. Siriopol D, Hogas S, Voroneanu L, Onofriescu M, Apetrii M, Oleniuc M, et al. Predicting mortality in haemodialysis patients: a comparison between lung ultrasonography, bioimpedance data and echocardiography parameters. Nephrol Dial Transplant. 2013;28:2851-9.

32. Vitturi $N$, Dugo M, Soattin M, Simoni F, Maresca L, Zagatti R, et al. Lung ultrasound during hemodialysis: the role in the assessment of volume status. Int Urol Nephrol. 2014:46:169-74.

33. Chen W, Gassner B, Borner S, Nikolaev VO, Schlegel N, Waschke J, et al. Atrial natriuretic peptide enhances microvascular albumin permeability by the caveolae-mediated transcellular pathway. Cardiovasc Res. 2012;93:141-51.

34. Horwich TB, Kalantar-Zadeh K, MacLellan RW, Fonarow GC. Albumin levels predict survival in patients with systolic heart failure. Am Heart J. 2008;155:883-9.

35. Liu M, Chan CP, Yan BP, Zhang Q, Lam YY, Li RJ, et al. Albumin levels predict survival in patients with heart failure and preserved ejection fraction. Eur J Heart Fail. 2012:14:39-44.

36. Hesse B, Parving HH, Lund-Jacobsen $H$, Noer I. Transcapillary escape rate of albumin and right atrial pressure in chronic congestive heart failure before and after treatment. Circ Res. 1976;39:358-62.

37. Battin DL, Ali S, Shahbaz AU, Massie JD, Munir A, Davis Jr RC. Hypoalbuminemia and lymphocytopenia in patients with decompensated biventricular failure. Am J Med Sci. 2010;339:31-5.

38. Shah R, Gayat E, Januzzi Jr JL, Sato N, Cohen-Solal A, diSomma S, et al. Body mass index and mortality in acutely decompensated heart failure across the world: a global obesity paradox. J Am Coll Cardiol. 2014;63:778-85.

39. Kenchaiah S, Pocock SJ, Wang D, Finn PV, Zornoff LA, Skali H, et al. Body mass index and prognosis in patients with chronic heart failure: insights from the Candesartan in Heart failure: Assessment of Reduction in Mortality and morbidity (CHARM) program. Circulation. 2007:116:627-36.

40. Enia G, Torino C, Panuccio V, Tripepi R, Postorino M, Aliotta R, et al. Asymptomatic pulmonary congestion and physical functioning in hemodialysis patients. Clin J Am Soc Nephrol. 2013;8:1343-8.

\section{Submit your next manuscript to BioMed Central and we will help you at every step:}

- We accept pre-submission inquiries

- Our selector tool helps you to find the most relevant journal

- We provide round the clock customer support

- Convenient online submission

- Thorough peer review

- Inclusion in PubMed and all major indexing services

- Maximum visibility for your research

Submit your manuscript at www.biomedcentral.com/submit
) Biomed Central 